\title{
Arteriovenous malformation of the uterus
}

\author{
Nazera Dodia, ${ }^{1}$ Suku George ${ }^{2}$
}

${ }^{1}$ Medical School, University of Manchester, Manchester, UK 2Stepping Hill Hospital,

Manchester, UK

\section{Correspondence to} Dr Nazera Dodia, drnazeradodia@gmail.com

Accepted 5 September 2015

\section{SUMMARY}

We present the case of a 54-year-old woman with intermittent right-sided abdominal pain. Ultrasound scans showed an unusual vascular appearance of the uterus with a thinned endometrium. Contrast CT led to a strong suspicion of an arteriovenous malformation of the uterus. The patient was successfully treated with a hysterectomy with salpingo-oophorectomy.

\section{BACKGROUND}

We report this case because uterine arteriovenous malformations are a rare but important diagnosis to consider in patients with abdominal pain of unknown cause and/or vaginal bleeding.

\section{CASE PRESENTATION}

A 54-year-old woman presented with intermittent right-sided abdominal pain, radiating to the left hip and groin.

This patient had a previous molar pregnancy. At the age of 25 years, she had suffered ovarian torsion during pregnancy, which was treated with a left salpingo-oophorectomy. She reached an early menopause at the age of 36 years, which was not investigated. She did not receive any hormone replacement therapy. Three years prior to developing symptoms of an arteriovenous malformation, she had undergone a rectocele repair. This patient's mother had suffered a vulval carcinoma.

On bimanual examination, the uterus felt pulsatile, but was a normal size.

\section{INVESTIGATIONS}

An initial transvaginal ultrasound scan showed an unusual vascular appearance of the uterus (figure 1). Biochemically, our patient was normal. Luteinising hormone and follicle-stimulating hormone were in the menopausal range, tumour markers were normal with a cancer antigen 125 of $4 \mathrm{U} / \mathrm{mL}$ (normal range $<35 \mathrm{U} / \mathrm{mL}$ ), carcinoembryonic antigen of $3 \mu \mathrm{g} / \mathrm{L}$ (normal range $<2.5 \mu \mathrm{g} / \mathrm{L}$ ) and human chorionic gonadotropin of $3 \mathrm{mIU} / \mathrm{mL}$ (normal postmenopausal range $<9.5 \mathrm{mIU} / \mathrm{mL}$ ).

A second transvaginal ultrasound scan showed a uterus with increased vasculature and a thin endometrium (figure 2). A small amount of fluid was found in the endometrial cavity; however, there was no free fluid in the abdomen, nor were there any adnexal masses.

It was decided at the multidisciplinary team meeting to perform MRI and repeat ultrasound scan 4 months later, as there was no clinical or radiological evidence of malignancy. MRI was consistent with findings on ultrasound scan (figure 3).
The repeat ultrasound scan showed similar features, but with increasing vascularity in the uterus with very little myometrium (figure 4).

After further multidisciplinary team discussion, a contrast CT was performed, which showed early filling of pelvic veins (figure 5).

\section{DIFFERENTIAL DIAGNOSIS}

A 54-year-old woman presenting with intermittent right-sided abdominal pain radiating to the hip and groin may have pathology in the bowel (constipation, diverticular disease or a hernia), renal system (renal calculi) or gynaecological system (ovarian cyst or tumour).

Once the common presentations described above are ruled out, alternate diagnoses must be considered. If a uterine ultrasound scan shows altered vascularity, the main differential diagnoses include arteriovenous malformation, choriocarcinoma and placental site trophoblastic tumour. Haematogenous cancer markers are then useful to help exclude malignant causes. However, even in the presence of normal tumour markers, a nonhuman chorionic gonadotropin-secreting trophoblastic tumour is still a differential diagnosis.

\section{TREATMENT}

It was decided at the multidisciplinary team meeting that open hysterectomy with salpingooophorectomy was safer than embolisation therapy in this case. This is because hysterectomy would be safe and effective if the lesion was cancerous, however, embolisation therapy would not be. Although cancer markers were normal, there was still the possibility of a non-human chorionic gonadotropin-secreting trophoblastic tumour. Furthermore, fertility preservation, which is a big advantage of embolisation therapy, was not a concern for this patient. An open operative approach was chosen over laparoscopic surgery

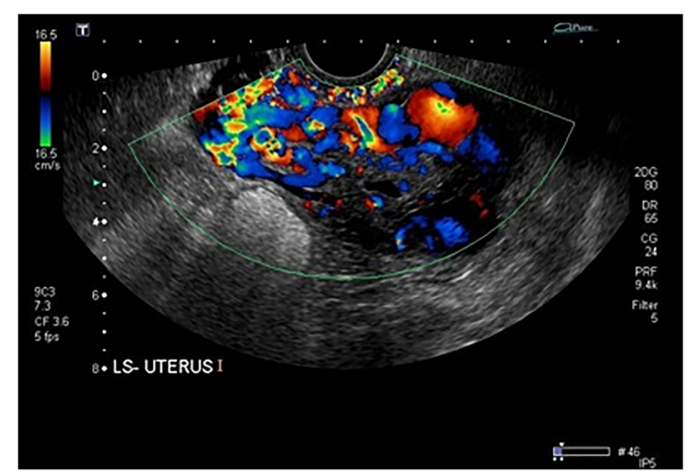

Figure 1 Extensive periuterine vascularity involving myometrium. No obvious masses seen. 


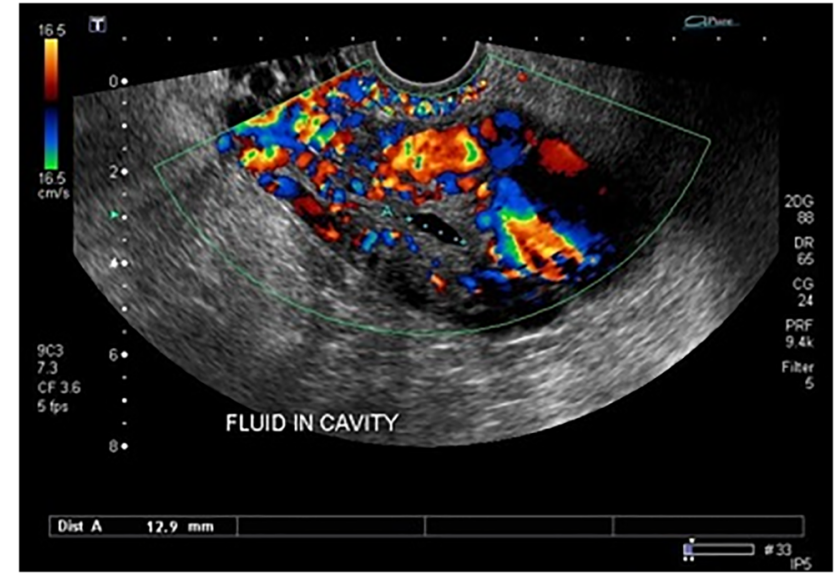

Figure 2 Retroverted uterus, appearing bulky in size. Entire myometrium is infiltrated with enlarged vessels with increased flow. No masses or pelvic free fluid can be seen.

because many of the vessels in the key pedicles were over $7 \mathrm{~mm}$ in width, rendering laparoscopic sealers ineffective. Therefore, an open approach was deemed safer. The patient accepted a hysterectomy.

\section{OUTCOME AND FOLLOW-UP}

The histology report showed an area of increased vascularity at the uterine fundus, with ill-defined thickening. Dilated blood vessels were observed in the thickened areas, some of which were filled with clots. The myometrium exhibited vascular

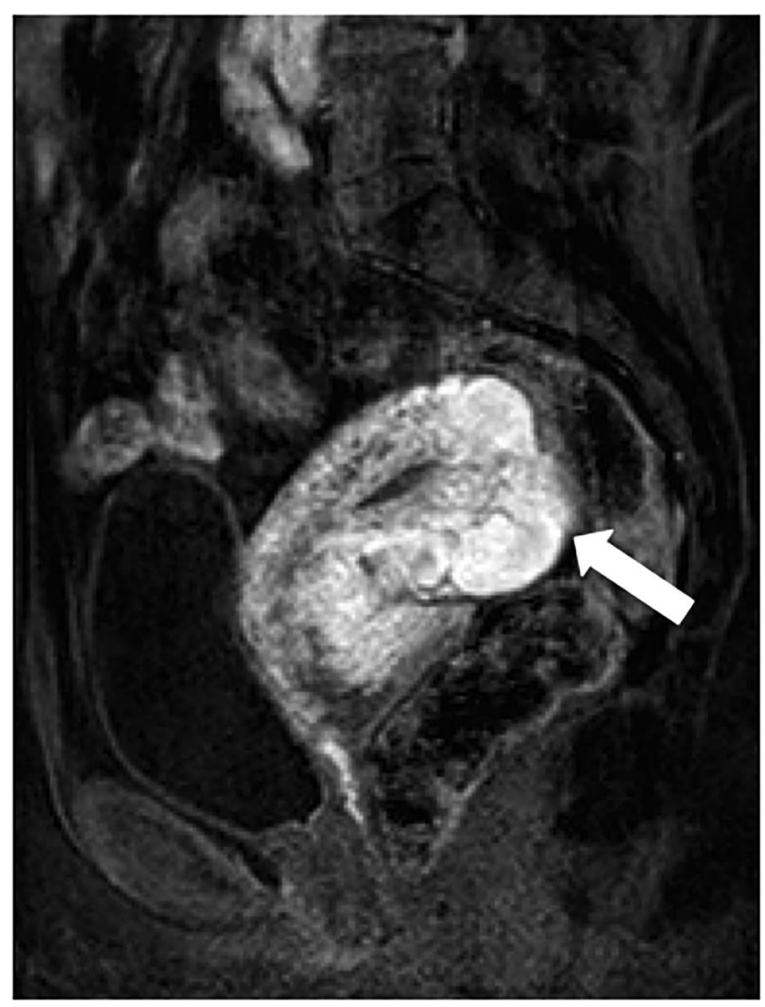

Figure 3 T2-weighted sagittal view on MRI of the pelvis and abdomen. Trace of fluid seen in the endometrial cavity. Multiple dilated vessels seen coursing through myometrium, the largest lying towards the fundus, with a diameter of $2.6 \mathrm{~cm}$ (see arrow). Rectum contains faecal matter. No masses identified.

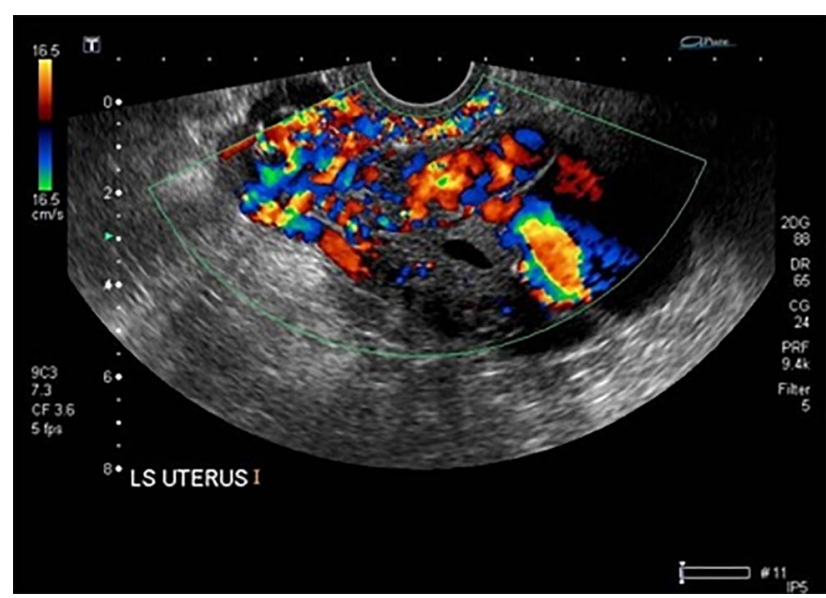

Figure 4 Unusually increased vascularity virtually replacing myometrium with large vascular lakes.

lesions comprising an admixture of arteries and large dilated veins. The vessels were lined by flattened, regular endothelial cells.

The lesion involved the entire uterine wall but was more prominent posteriorly and extended into the cervix. No evidence of trophoblastic neoplasia or malignancy was found. The uterine serosa was healthy; the endometrium was inactive with a benign polyp. The right fallopian tubes and right ovary were healthy. The left ovary had been removed in a previous surgery.

Symptoms resolved following hysterectomy.

\section{DISCUSSION}

Uterine arteriovenous malformations can be acquired by any trauma to the uterus. Pregnancies, especially if complicated, can trigger a latent arteriovenous malformation into a symptomatic phase. Gestational trophoblastic disease and gynaecological malignancies are also possible causes. ${ }^{1}$ In this case, the history of molar pregnancy and ovarian torsion could be aetiological factors.

The hormones of pregnancy and the menstrual cycle may play a role in the pathogenesis, as most patients present at a reproductive age. ${ }^{1}$ However, congenital cases have been reported in patients with cyanotic congenital heart disease. ${ }^{2}$ The youngest case of congenital arteriovenous malformation of the uterus reported was a 34-week stillborn fetus. ${ }^{3}$

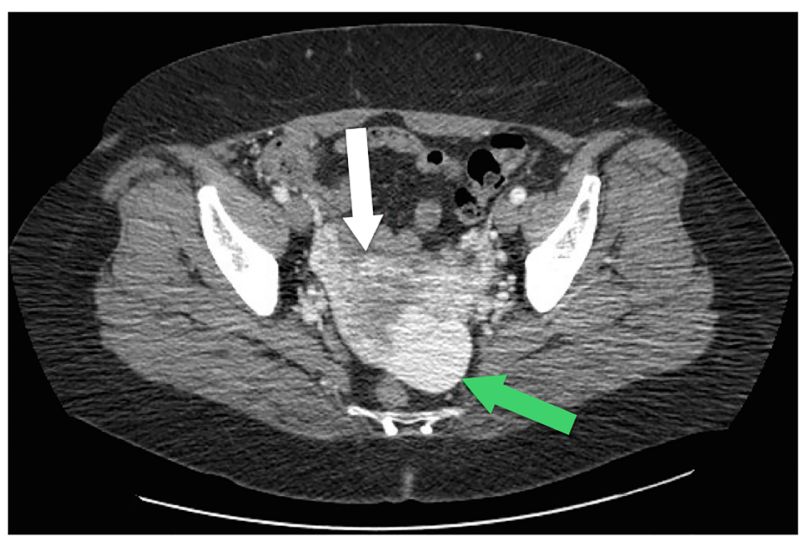

Figure 5 Transverse view on contrast CT scan showing dilated associated pelvic vessels. White arrow shows uterus; green arrow shows dilated vessels. 
Arteriovenous malformations of the uterus have been associated with missed abortion, medical abortion, scar pregnancy and secondary postpartum haemorrhage.

Among the presenting symptoms that have been reported are persistent menorrhagia, symptomatic anaemia, dysmenorrhoea, dyspareunia, postmenopausal bleeding and abdominal pain. Some patients are asymptomatic. Acute presentations of vaginal haemorrhage can occur.

Classically, angiography has been used to diagnose uterine arteriovenous malformations, and remains the gold standard. This is an invasive procedure; hence MRI, CT and ultrasound scans have been utilised. Ultrasound scanning has been successful in providing a quick and accurate diagnosis. Colour Doppler ultrasound shows a classic 'mosaic' pattern, while spectral Doppler shows a high-velocity, low-resistance flow. ${ }^{4}$ As with our patient, many suspected cases are diagnosed at hysterectomy.

In cases of acute blood loss, a Foley catheter can be inserted into the uterus and the bulb inflated to block the flow of blood temporarily. Intravenous oestrogen and 15-methyl prostaglandin F $2 \alpha$ have also been useful in the management of acute haemorrhage. ${ }^{5}$ A single intramuscular bolus of methylergonovine has classically been successfully used in the acute phase. ${ }^{6}$

Percutaneous transcatheter embolisation has been used as definitive treatment. A recent study with a relatively large cohort of 42 patients was in favour of embolisation therapy, with an $88 \%$ success rate. However, $17 \%$ of patients suffered from a postembolisation syndrome, featuring pelvic pain and fever. These symptoms were self-limiting. ${ }^{7}$ Along with postembolisation syndrome, a less than $100 \%$ success rate is the main other disadvantage. The advantages of embolisation are that it is fertility preserving and general anaesthesia is not required.

It was previously feared that reducing the uterine blood supply with this therapy would render the patient infertile. Several successful pregnancies after embolisation therapy have been reported. ${ }^{7}$ The collateral vessels of the uterus seem to provide a sufficient blood supply to maintain a pregnancy, although there is a higher risk of spontaneous abortion, preterm delivery and placental complications. ${ }^{1}$

Another treatment option is laparoscopic bipolar coagulation of the uterine vessels. ${ }^{8}$ This is also fertility preserving. The disadvantage to bipolar coagulation is that general anaesthesia is required and, as with embolisation, there is a risk of recurrence of symptoms. Bipolar coagulation is regarded to be safer than embolisation in terms of radiation exposure.

Hysterectomy, while invasive, is a definitive treatment resulting in resolution of symptoms, and allows histological examination. Increased risk of intraoperative haemorrhage, venous thromboembolism and infection are complications of surgery. A laparoscopic approach minimises these risks and is commonly used. In this case, unfortunately, laparoscopic surgery was not a safe option due to the large size of the vessels. With both laparoscopic and open hysterectomy, there is the need for hospitalisation and general anaesthesia. Time needs to be allowed for postoperative recovery, which varies depending on the presence of complications.
Gonadotropin-releasing hormone agonists have also been used successfully in long-term management. ${ }^{9}$ This therapy is non-invasive and allows treatment to be provided on an outpatient basis, which is an advantage over all other treatment options. However, side effects of medication include symptoms of hypo-oestrogenism, which can be poorly tolerated.

It is theorised that decreasing oestrogen levels using gonadotropin-releasing hormone agonists decreases angiogenesis in the endometrium, as oestrogen receptors in the endometrium allow the proliferation of vessels when stimulated. ${ }^{9}$ However, our patient developed her illness 18 years after menopause, suggesting that there are other pathogenic factors to be investigated.

\section{Learning points}

- An arteriovenous malformation is an abnormal communication between arteries and veins.

- Uterine arteriovenous malformations are a rare but important diagnosis to consider in patients presenting with low abdominal pain or abnormal vaginal bleeding.

- Ultrasound scanning is a useful first-line investigation.

- Treatment options vary, with embolisation therapy being the most popular fertility-preserving therapy.

Contributors ND performed the literature review, case note analysis and write up of the report. SG had the original idea to publish, and performed manuscript editing.

Competing interests None declared.

Patient consent Obtained.

Provenance and peer review Not commissioned; externally peer reviewed.

\section{REFERENCES}

1 Hoffman MK, Meilstrup JW, Shackelford DP, et al. Arteriovenous malformations of the uterus: an uncommon cause of vaginal bleeding. Obstet Gynecol Surv 1997; 52:736-40

2 Wijesekera NT, Padley SP, Kazmi F, et al. Embolization of uterine arteriovenous malformations associated with cyanotic congenital heart disease. Cardiovasc Intervent Radiol 2009;32:1075-9.

3 Kasznica J, Nisar N. Congenital vascular malformation of the uterus in a stillborn: a case report. Hum Pathol 1995;26:240-1.

4 O'Brien P, Neyastani A, Buckley AR, et al. Uterine arteriovenous malformations: from diagnosis to treatment. J Ultrasound Med 2006;25:1387-92.

5 Brown RL, Van Moore A, Smythe AR. Arteriographic management of uterine arteriovenous fistula. Am J Obstet Gynecol 1986;155:491-3.

6 Flynn MK, Levine D. The noninvasive diagnosis and management of a uterine arteriovenous malformation. Obstet Gynecol 1996;88:650-2.

7 Wang Z, Chen J, Shi H, et al. Efficacy and safety of embolization in iatrogenic traumatic uterine vascular malformations. Clin Radiol 2012;67:541-5.

8 Wu YC, Liu WM, Yuan CC, et al. Successful treatment of symptomatic arteriovenous malformation of the uterus using laparoscopic bipolar coagulation of uterine vessels. Fertil Steril 2001;76:1270-1.

9 Nonaka T, Yahata T, Kashima K, et al. Resolution of uterine arteriovenous malformation and successful pregnancy after treatment with a gonadotropin-releasing hormone agonist. Obstet Gynecol 2011;117(2 Pt 2):452-5. 


\section{Rare disease}

Copyright 2015 BMJ Publishing Group. All rights reserved. For permission to reuse any of this content visit http://group.bmj.com/group/rights-licensing/permissions.

BMJ Case Report Fellows may re-use this article for personal use and teaching without any further permission.

Become a Fellow of BMJ Case Reports today and you can:

- Submit as many cases as you like

- Enjoy fast sympathetic peer review and rapid publication of accepted articles

- Access all the published articles

- Re-use any of the published material for personal use and teaching without further permission

For information on Institutional Fellowships contact consortiasales@bmjgroup.com

Visit casereports.bmj.com for more articles like this and to become a Fellow 